tron beams, and since the extremely high dopant diffusivities observed are compatible with the formation of a molten region, the thermal hypothesis is strongly supported by some experiments. On the other hand, $X$ rays have been observed to enhance the diffusion of metal contacts into the surface of semiconductors and photoionisation may enable charged interstitial impurities to move more easily to vacancies in the crystal lattice. Certainly melting is not essential for removal of ion implantation damage.

This kind of debate has already been conducted in a closely related area. The use of a laser heam to recrystallise locally a chalcogenide glass (a multicomponent amorphous semiconductor such as sputtered Ge-Te-As) was proposed several years ago as an optical storage technique. Even in this case, the relative role of thermal and photostructural effects remains obscure.

\section{Damn the dogma}

from John C. Allen

A TOURIST hotel set in the mountains $350 \mathrm{~km}$ North of Oslo was the venue for a recent meeting on Chalones*, a most controversial subject in cell biology. The original hypothesis, which, alas, has been elevated to the status of a dogma, proposed that tissue homeostasis is maintained by mitotic inhibitors termed chalones, which are non-cytotoxic, tissue specific and species nonspecific, and which are secreted by the tissue over which they exert their effect. The theory has been beset by problems ever since its formulation by Bullough and Laurence in 1960, not the least heing that in 18 years of intensive research there has been no confirmed report of the isolation of a pure chalone, much less any firm molecular identification. Nevertheless, the scientific importance and potential clinical uses of such substances are manifold, and the literature abounds with reports of partially purified epidermal. granulocytic and $1 y m$ phocytic chalones. Certainly, the concept has stimulated an immense amount of research, and it was fitting that the participants at the meeting demonstrated their debt to William Bullough (Birkbeck College, London) by presenting him with a portrait to mark his forthcoming retirement.

The organisers had invited two eminent 'devil's advocates' from more respectable realms. A. B. Pardee (Sidnev Farber Cancer Institute. Boston) and

John C. Allen is Reader in Biochemistry at the North E. Wales Institute, Kelsterton College, Clwyd.
R. W. Holley (Salk Institute, San Diego) fulfilled this difficult role admirably and with unanimity. In their summing up, Pardee believed that there was no evidence for the existence of chalones as defined by Bullough, and Holley exhorted all to stop concerning themselves with restrictive definitions with the memorable phrase 'damn the dogma'. However, both felt that endogenous inhibitors do exist and that workers should now set about purifying them from associated nonspecific activity.

Indeed there was no shortage of inhibitors: over 30 were described, with molecular weights ranging from 100,000 to 300 ! Doubtless, several will prove to be identical, and many trivial. Among the more interesting is that painstakingly isolated from blood by W. R. Paukovits (Cancer Research Institute, University of Vienna.) This is an SH-containing pentapeptide of molecular weight 590 which apparently contains a pyroglutamyl N-terminus. It exerts a fine control over granulocyte proliferation but is inert towards thymic lymphocytes. The nearest we have to a pure lymphocyte chalone is the thymus-derived peptide of J, C. Houck (Virginia Mason Research Center, Seattle). This substance, of molecular weight 1400 and purified by final cellulose chromatography, inhibits lymphoblast formation by $50 \%$ in mixed lymphocyte culture at only $1 \mu \mathrm{g} \mathrm{ml} \mathrm{ml}^{-1}$. Houck informally revealed that sequencing is well under way. It can only be hoped that his characteristic optimism will this time be justified, and that a homogeneous preparation is in the offing.

Problems associated with isolation received thorough discussion. G. Isaksson-Forsen (University of Oslo) and A. Quirk (University of Newcastle) independently reported aggregation with concomitant loss of activity during purification of epidermal inhibitors. Other explanations for chalones' elusiveness were suggested, including their secretion as zymogens and their tendency to adhere to larger molecules. However, there is little firm evidence, and such effects may turn out to be 'laboratory specific'.

Unfortunately, much work reported was on impure and even crude tissue extracts. Surely, the dangers of spurious effects from artefacts should be appreciated by now? J. C. Allen (North E. Wales Institute) described work with synchronised lymphoma cells which showed how the simple molecule spermine could exert a very specific inhi*An International Symposium on Chalones in Normal and Malignant Cell Populations was held at Geilo, Norway on 29 October--2 November It was sponsored by the Norwegian Cancer Society (Institute of Pathology. University of Oslo). bitory effect. H. R. Maurer (Freie Universität, Berlin) warned of the dangers of reliance on the measurement of tritiated thymidine as sole indicator of cell proliferation, and advocated colony counting in preference. It was agreed that no single assay is satisfactory; perhaps the best plan is to adopt a simple in vitro screening procedure and to substantiate the results with a series of assays which must include an in vivo test.

Recent studies on epidermal inhibitors have provided some intriguing pointers to their true specificity and perhaps to in vivo function. A. Thornley (Witwatersrand University) has discovered that his epidermal chalone has an inhibitory effect not only on epidermis, but also on other specifically epithelial tissues including lung, trachea and bladder. This substance may thus be cell line, rather than tissue specific. In addition. S. Bertsch (German Cancer Research Centre. Heidelberg) has partially purified an inhihitor from a keratinised epithelial tumour of the bladder. This was active only on keratinised, and hence differentiated epithelial cells. This is evidence, albeit insubstantial, that the inhibitor was acting to maintain differentiation rather than as a cell cycle modulator.

Thus many workers have already subconsciously rejected the 'dogma' and have adopted a simple operational definition of the useful word 'chalone'. Perhaps the most encouraging aspect of the meeting was the healthy selfcriticism. There is now only one reason why chalone research should not move into the mainstream of cell biology, and that is the lack of a homogeneous preparation. This sense of frustration is understandable, but the cell biologists will have to be patient and give the biochemists time to catch up.

\section{Status of biocontrol in medical entomology}

OVER the past two decades, there have been major and continuing advances towards practical biological control of arthropod vectors of disease. Until the late 1950 s, biocontrol in medical entomology meant little more than the (sometimes ecologically irresponsible) use of larvivorous fish-primarily Gambusia affinis subspp. Since then, though, the growing number of investigators in this field have increasingly concentrated upon the feasibility of control by mass-produced microorganisms and parasites. 